\title{
PERSPECTIVAS SOBRE O DESENVOLVIMENTO DA ASSISTÊNCIA À SAÚDE NO BRASIL
}

\author{
Perspectives on the development of healthcare in Brazil
}

Perspectivas sobre el desarrollo de la atención de salud en Brasil

Received: august $/ 2020$

Accepted: september/2020

Available online: september/2020

Ernesto Mifano Honigsberg, Graduando em Ciências Sociais e Pesquisador de Iniciação Científica, FFLCH-USP e CEM (CEPID-FAPESP), Brasil

E-mail: netohonigsberg@yahoo.com.br

\begin{abstract}
Resumo: A partir da leitura das obras de Menicucci (2007) e Braga (2018), o presente artigo busca apresentar um breve panorama da história da assistência à saúde no Brasil desde meados do século XX - com ênfase especial nas ambíguas relações observadas entre os setores público e privado no período - para assim construir uma visão ampla sobre os processos que constituíram a saúde brasileira como um todo e, mais particularmente, sobre a formação e a implementação do Sistema do Único de Saúde (SUS). Ainda que apoiadas em referenciais teóricos distintos (visões neo-institucionalista e gramsciana, respectivamente), se combinadas, ambas as análises podem trazer importantes interpretações para a constituição do atual sistema de saúde brasileiro, que as autoras chamam de dual ou híbrido. No caso da constituição do Sistema Único de Saúde, os livros mostram como os efeitos de "path dependence" e "feedback" das políticas anteriores limitaram severamente sua implantação e, posteriormente, como as entidades empresariais de saúde têm atuado num processo de garantir seus interesses particulares, de forma a enfraquecer o projeto publicista de saúde previsto na Constituição de 1988.
\end{abstract}

Palavras-chave: Assistência à Saúde, Políticas públicas de saúde, Saúde Coletiva, Sistema Único de Saúde.

Abstract: From the reading of the works of Menicucci (2007) and Braga (2018), this article seeks to present a brief overview of the history of healthcare in Brazil since the mid-twentieth century - with special emphasis on the ambiguous relations observed between the public and private sectors in the period - in order to build a broad view on the processes that constituted Brazilian health as a whole and, more particularly, on the formation and 
implementation of the Unified Health System (SUS). Although supported by distinct theoretical references (neo-institutionalist and gramscian views, respectively), if combined, both analyzes can bring important interpretations to the constitution of the current Brazilian health system, which the authors call dual or hybrid. In the case of the constitution of the Unified Health System, the books show how the effects of "path dependence" and "feedback" of previous policies severely limited its implementation and, later, how business health entities have acted in a process of guaranteeing their own private interests in order to undermine the public health project foreseen in the 1988 Constitution.

Keywords: Healthcare, Health public policy, Public health; Unified Health System.

Resumen: Al leer los trabajos de Menicucci (2007) y Braga (2018), este artículo busca presentar una breve descripción de la historia de la atención médica en Brasil desde mediados del siglo XX, con especial énfasis en las relaciones ambiguas observadas entre los sectores públicos y privado en el período, con el fin de buscar construir una visión amplia sobre los procesos que constituyeron la salud brasileña en su conjunto y, más particularmente, sobre la formación y implementación del Sistema Único de Salud (SUS). Aunque respaldados por distintas referencias teóricas (puntos de vista neoinstitucionalistas y gramscianos, respectivamente), si se combinan, ambos análisis pueden aportar interpretaciones importantes a la constitución del sistema de salud brasileño actual, que las autoras llaman dual o híbrido. En el caso de la constitución del Sistema Único de Salud, los libros muestran cómo los efectos de "path dependence" y "feedback" de políticas anteriores limitaron severamente su implementación y, posteriormente, cómo las entidades corporativas de salud han actuado en un proceso de garantía de sus intereses privados, de manera a debilitar el proyecto para la salud pública previsto en la Constitución de 1988.

Palabras clave: Atención de salud, Políticas de salud pública, Salud colectiva, Sistema Unificado de Salud.

\section{INTRODUÇÃ̃ ${ }^{1}$}

A partir da leitura das obras "Público e privado na política de assistência à saúde no Brasil: atores, processos e trajetórias", de Telma Menicucci (2007) e "Empresariado e políticas públicas de saúde no Brasil contemporâneo", de Ialê Falleiros Braga (2018), o presente artigo busca apresentar um breve panorama da história da assistência à saúde no Brasil desde meados do século XX - com ênfase especial nas ambíguas relações observadas entre os setores público e privado no período - para assim tentar construir uma visão ampla

\footnotetext{
${ }^{1} \mathrm{O}$ presente artigo foi produzido no âmbito de minha pesquisa de Iniciação Científica intitulada "Caminhos das instituições de assistência à saúde no Brasil: Um estudo da história política do Sistema Único de Saúde", que é realizada no Centro de Estudos da Metrópole (CEPID-FAPESP). Agradeço à FAPESP pela bolsa de pesquisa concedida na linha de fomento BCO - Iniciação Científica - Fluxo Contínuo (processo no 2019/09162-0, Fundação de Amparo à Pesquisa do Estado de São Paulo).
} 
sobre os processos que constituíram a saúde brasileira como um todo e, mais particularmente, sobre a formação e a implementação do Sistema do Único de Saúde (SUS).

Por uma perspectiva, os dois livros parecem bastante complementares entre si, temática e até mesmo cronologicamente, já que o livro de Menicucci foca principalmente nas políticas de saúde brasileiras de 1930 (mais detalhadamente a partir de 1960) até o final dos anos 1990 (processo de criação do SUS, implementação ainda incipiente), enquanto o de Braga está principalmente voltado ao processo de implementação efetiva do SUS, entre as décadas de 1990 e 2010; além disso, ambos os livros buscam dar bastante ênfase nas ambíguas relações entre o setor público (Ministério da Saúde, políticas estatais e, posteriormente, o SUS) e o setor privado (hospitais, médicos autônomos, empresas de medicina de grupo, planos de seguro, entidades empresariais...) da saúde - explorando o caráter "dual" ou híbrido da assistência à saúde no Brasil, especialmente após a implementação do Sistema Único de Saúde.

Ao mesmo tempo, os livros guardam algumas diferenças importantes, tanto nas abordagens teóricas, quanto em suas distintas interpretações ou olhares sobre a trajetória das políticas de saúde brasileiras, temas estes que serão desenvolvidos mais adiante. A ideia será fazer essa comparação entre os textos, observando assim algumas complementaridades, divergências, oposições e os possíveis diálogos profícuos que ambos podem gerar se lidos conjuntamente.

Este artigo consiste em, primeiramente, uma apresentação e resenha detalhada de cada um dos livros - apresentando seus referenciais teóricos, teses e principais argumentos, construindo, assim, um panorama da história da assistência à saúde no Brasil. Posteriormente, será realizada uma análise comparativa entre os trabalhos, de forma a realizar uma reflexão mais complexa sobre esses processos e a constituição do Sistema Único de Saúde. 
“Público e Privado na Política de Assistência à Saúde no Brasil: atores, processos e trajetórias"

O livro de Menicucci, já com mais de uma década de idade, é referência para o campo e uma ótima ferramenta para se compreender os processos pelos quais as políticas públicas de assistência à saúde se desenvolveram no Brasil, e também o setor privado - por influência ou em oposição a essas mesmas políticas. É também uma excelente sistematização da história do desenvolvimento da assistência à saúde no Brasil desde 1930, pontuando assim as mudanças e, principalmente, as continuidades no setor - contrariando outros estudos, que "desprezaram" o passado ao tentar fazer uma interpretação contemporânea do sistema de saúde brasileiro. A análise sobre a interação entre o setor público e o privado presente no texto é bastante detalhada, e importante para a compreensão dos processos que o País atravessou.

Metodologicamente, como a autora apresenta no primeiro capítulo, o livro se insere numa perspectiva neo-institucionalista ou do novo institucionalismo. A partir da definição de "instituição" como "regras do jogo", formais ou informais, ou limites que estruturam a interação humana (Pierson, 1993, 1994 apud Menicucci, 2007, P. 25). Essa perspectiva consiste, em uma linha, na ideia de que os legados das escolhas políticas previamente estabelecidas limitam as escolhas políticas futuras (path dependence, condicionamento de trajetória), marcando a importância das instituições não só como arenas, mas também como atores políticos. Segundo o artigo de Fernandes (2002):

Path dependency significa que um país, ao iniciar uma trilha, tem os custos aumentados para revertê-la. Existirão outros pontos de escolha, mas as barreiras de certos arranjos institucionais obstruirão uma reversão fácil da escolha inicial (LEVI, 1997, p. 22 apud FERNANDES, 2002, p. 79)

Um desses efeitos das escolhas prévias é propiciar a constituição de atores com agendas organizadas, "identidades e clivagens sociais que se expressam em distintas 
compreensões e preferências quanto às alternativas de políticas” (MENICUCCI, 2007, p.17), o chamado "efeito de feedback".

Assim, por esta concepção, nada nesse mundo das instituições acontece de maneira completamente espontânea ou disruptiva, mas sempre como fruto ou pelo menos influência, em alguma medida, de escolhas políticas anteriores - sem, claro, desconsiderar a conjuntura como elemento também determinante na tomada de decisões. A ideia do neo-institucionalismo é:

combinar tanto a agência quanto a estrutura em qualquer explicação do comportamento e dos resultados sociais, rompendo com modelos explicativos polarizados ao reconhecer que as preferências dos indivíduos vêm de estruturas e experiências passadas, mas que, ao mesmo tempo, é preciso ter agentes que sejam portadores dos imperativos estruturais e que no processo de reproduzir as estruturas sejam capazes também de remodelá-las (GOODIN, 1996 apud MENICUCCI, 2007, p. 21).

Por isso, para a autora, é tão importante revisitar a trajetória das políticas públicas de saúde brasileiras para poder melhor compreender o fenômeno do SUS e a assistência à saúde no Brasil, de forma geral - que, por essa ótica, não seria resultado um processo de total ruptura, mas pelo contrário, em muitos aspectos seria uma continuação de uma série de práticas de assistência à saúde que foram consolidadas durante décadas no Brasil. Para construir essa "visão global" da saúde brasileira, o livro também dá bastante ênfase à consolidação e regulação da assistência privada, em paralelo à constituição do SUS, e em alguma medida tão importante quanto.

O capítulo 2 (“A constituição do mix privado/público na assistência à saúde”), detalha com uma série de argumentos históricos como, já desde a década de 1930, mas especialmente de 1960, os sucessivos incentivos do governo estruturam um setor privado da saúde muito forte e organizado no Brasil, ampliando enormemente a população com assistência garantida. Ao mesmo tempo, o não-desenvolvimento (ou subdesenvolvimento) da saúde pública, deixou-a completamente vulnerável a esse setor privado e seus interesses. Por fim, mostra que a saúde no Brasil nasce vinculada aos contratos de trabalho, de forma corporativista, - 
primeiro com as IAPs (Institutos de Aposentadorias e Pensões, vários setores tinham o seu: marítimos, bancários, industriais, servidores públicos e assim por diante. Era a instituição responsável por organizar a Saúde e a previdência dos trabalhadores da categoria. Por vezes criavam hospitais próprios, mas, via de regra, compravam serviços privados e se credenciavam em hospitais particulares); depois com o INPS (Instituto Nacional de Previdência Social, substitui IAPs em 1966, como política centralizadora do governo militar. Incentiva que empresas financiem parcialmente a saúde dos trabalhadores em convênios tripartites: Estado - empresa empregadora - empresa de saúde), que divide os trabalhadores por contrato de trabalho - o que enfraquece, já de saída, a união dos trabalhadores em prol de uma saúde pública e universal. Essa série de escolhas políticas e o consequente fortalecimento da rede privada, ainda que fortemente regulada e mediada pelo Estado, terá impactos bastante relevantes no final do século, como se verá adiante.

O capítulo terceiro (“As formas privadas de assistência à saúde”) se dedica a escrutinar o setor privado da saúde, no mesmo período do capítulo anterior. Mostrando como o efeito "feedback" das políticas de saúde apresentadas formou um setor privado grande e com diversas modalidades de assistência, com agentes e interesses fortalecidos no mercado e na atuação na arena pública. Esse mercado começa a ter um crescimento exponencial na década de 60 com a criação de empresas de medicina de grupo, cooperativas médicas e seguradoras e o subsídio do governo, direto e indireto, aos convênios-empresa. Na década de 80 a saúde se desenvolve para além do campo do trabalho, com o surgimento dos planos de saúde individuais, voltados aos mais ricos. O setor privado vai do status de "complementar" a “suplementar", e ganha cada vez mais autonomia. Nesse momento, acontecem sérias disputas pelo mercado de consumidores da saúde entre empresas de medicina de grupo e cooperativas médicas, e também entre prestadores e compradores de serviços - em resposta a esse 
movimento de concorrência, surgem organizações, articuladas para a defesa dos interesses de cada um desses grupos empresariais.

$\mathrm{Na}$ década de 80 a saúde pública era considerada de péssima qualidade, e a crise financeira no período atingiu fortemente o setor privado de saúde. Ao mesmo tempo, ocorria o processo de abertura democrática e de elaboração de uma nova constituição para o País, permitindo a entrada e a participação de novos atores na arena do debate público. Para a autora, essa conjuntura excepcional possibilitou uma grande inovação na saúde brasileira: o surgimento do Sistema Único de Saúde. O capítulo 4 (“A reforma da política de saúde") apresenta este processo, detalhando a formação e estratégia do movimento sanitarista, que liderou politicamente a reforma da saúde, e também os debates em relação à Constituição de 1988. É inegável que o SUS seja uma grande inovação, ampliando e garantindo enormemente o direito à saúde, no entanto a autora procura também demonstrar como o efeito das políticas anteriores limitou severamente sua implementação. Então, por mais que segundo sua Lei Orgânica o SUS seja universal, na prática ele não o é - estando voltado principalmente à faixa de população de mais baixa renda, enquanto a população mais rica continua comprando dos serviços privados. Além disso, a tendência neoliberal de governos como o de Collor, e o baixo financiamento que o SUS recebeu desde sempre acabaram enfraquecendo muito o projeto publicista para a saúde e fortaleceram a saúde "híbrida". Nas décadas de 80 e 90, as empresas privadas de saúde obtiveram um crescimento nunca antes visto, e se o texto constitucional "não falava" sobre saúde privada, no final da década de 90 surgiram as primeiras leis de regulamentação dos planos de saúde, formalizando a política dual da saúde no Brasil.

Complementar ao livro de Menicucci, e até levando mais a fundo a ideia de continuidade das políticas, o artigo "Infiltrating the State", de Tulia Falleti, mostra como, antes mesmo da constituinte de 1988, o movimento sanitarista já havia conseguido se “infiltrar" no Estado, de forma que boa parte da estrutura do SUS já acontecia na prática 
desde o final do período militar, ainda na década de 70. Isso aconteceu por uma confluência de interesses, já que o governo militar buscava aumentar a presença do Estado no território brasileiro, além de "acalmar" ativistas rurais - assim é criada a FUNRURAL (Fundo de Assistência ao Trabalhador Rural), em 1971, garantindo assistência médica, ainda que básica, aos trabalhadores rurais, informais e desempregados antes descobertos desse direito, e o PIASS (Programa de Interiorização das Ações de Saúde e Saneamento), em 1976, que cria miniestações de saúde sanitária-preventiva em pequenas cidades do Nordeste e Minas Gerais, recrutando e treinando muitos novos agentes de saúde. O sucesso do PIASS, levou à criação do plano das AIS (Ações Integradas de Saúde), novamente muito efetivo. Esses programas fortaleceram muito a ideia de descentralização, hierarquização e municipalização da saúde, e consistiram na maior ampliação de assistência à saúde já feita, em termos de quantidade de população coberta. Dessa forma, os sanitaristas conseguiram pôr em prática modelos de prevenção e saúde pública em larga escala - o que além de tudo, era muito barato para o governo. Assim, conclui a autora, o surgimento do SUS, descentralizado e universal, não aconteceu de forma abrupta, mas como resultado de um processo de quase 20 anos, que começou no seio do regime militar. Quando o SUS foi consolidado, na Constituinte, boa parte de suas bases já aconteciam na prática graças a esses elementos "subversivos" de esquerda, que se infiltraram no Estado e, lentamente, conseguiram introduzir mudanças políticas efetivas se utilizando do aparato estatal militar para atingir seus propósitos.

Voltando ao livro, o quinto capítulo ("A regulação da assistência à saúde suplementar") apresenta a tese de que a regulamentação da saúde privada, ocorrida no final dos anos 1990 e princípio dos 2000, é a consolidação do sistema de saúde dual brasileiro não um marco do neoliberalismo ou um apogeu da privatização, mas da interferência e regulação estatal da saúde privada. "Tal caráter [dual do sistema de saúde] se expressa na dupla institucionalidade, no duplo locus decisório e normativo e, fundamentalmente, na 
segmentação dos usuários” (MENICUCCI, 2007, P. 282), assim o SUS na prática ficou restrito ao setor dos que não podem arcar com planos privados de saúde e também não são cobertos por planos coletivos de trabalho, se tornando segmentado e não universal, diferentemente do que é apresentado no texto da Constituição. O Estado, por sua vez, passa a arcar com um duplo financiamento, o que mostra a falta de uma política global para a saúde, mas um mix de duas que coexistem, nem sempre tão harmonicamente.

Marco dessa regulamentação do setor privado é a criação da Agência Nacional da Saúde Suplementar, a ANS, entidade reguladora dos diversos grupos de saúde privada e palco do conflito de interesses entre esses grupos. A autora resume as atribuições da agência:

[...] estabelecer regras que viessem assegurar o desempenho por agentes privados de atividades consideradas relevantes de uma forma que atendesse a critérios de sustentabilidade econômica e social; [...] estimular a competição; fiscalizar a atividade, com o estabelecimento de regras e a aplicação de sanções; controlar preços; e fixar parâmetros para a assistência (MENICUCCI, 2007, p. 286/287).

A pesquisa de Menicucci demonstra como no Brasil existe um mix público/privado na saúde, caracterizando um peculiar sistema, dual e segmentado: parte público e igualitário, ligado à concepção do direito universal à saúde; parte particular, ligado às leis de mercado e ao poder aquisitivo ou inserção privilegiada no mercado de trabalho por parte de seus usuários. A tese buscou demonstrar como o legado de políticas desde 1930, mas principalmente de 1960, condicionaram o desenvolvimento posterior da assistência à saúde e fortaleceram muito o setor privado: estruturando atores e interesses, determinando padrões de comportamento difíceis de reverter e causando efeitos negativos sobre a capacidade governamental de prover serviços de saúde, pouco favoráveis à mudança de trajetória, além da desarticulação da população em geral da luta em prol de um projeto saúde efetivamente universal, público e igualitário. 


\section{"Empresariado e Políticas Públicas de Saúde no Brasil Contemporâneo"}

O livro de Braga, embora no primeiro capítulo também traga um breve panorama histórico das políticas de saúde brasileiras (onde inclusive o livro de Menicucci é nominalmente citado como importante referência), está principalmente focado nos anos mais recentes e, para além do projeto que foi construído pelo movimento sanitarista, em como se deu a implementação do SUS na prática - e como esse processo, por si, apresentou diversas particularidades e mudanças bastante radicais em relação ao projeto inicial e até mesmo ao que está expresso na Constituição Federal de 1988. A análise é centrada especialmente nas organizações empresariais de saúde, e seus impactos diretos e indiretos nas políticas nacionais de saúde brasileiras.

Como referencial teórico, o livro utiliza uma concepção baseada nas visões de Antonio Gramsci (2001a, 2001b, 2002), buscando entender a sociedade civil como local privilegiado no embate de forças distintas e as interfaces dessas forças com instituições estatais. Assim, objetiva compreender quais foram os grupos melhor estruturados e articulados, que conseguiram produzir consenso na construção de um projeto de sociedade, e mais especificamente no campo da saúde (pela visão gramsciana, “consenso” é visto num sentido de coerção, como o projeto que se torna hegemônico, dominante). Neste mesmo sentido, a contribuição teórica de Poulantzas (2000) também é relevante, trazendo a ideia de que a luta de classes é reproduzida dentro da própria estrutura do Estado e assim, dentro deste estão inscritas as visões e projetos dos variados grupos sociais organizados, de maneiras desiguais, seja como dominantes ou subalternas. Segundo a autora, por essa visão, Estado consistiria na:

[...] instância na qual se expressam relações entre os grupos sociais organizados, em condições desiguais, na esfera da produção econômica e na esfera política da sociedade civil. Essas organizações constroem visões de mundo distintas [...] e inscrevem, no âmbito dos aparelhos de Estado, de modo dominante ou subalterno, diferentes projetos para a sociedade" (BRAGA, 2018, p. 22). 
Esse "equilíbrio" entre as visões de classe dentro do Estado, contudo, favorece o capital. Assim, por essa chave, políticas sociais como o SUS representariam uma forma de obtenção de consenso para legitimar capitalismo e arrefecer as lutas sociais, que, uma vez incorporadas ao aparelho estatal, se enfraquecem.

A tese de Braga vê a reforma sanitária como parte de um consenso, surgido na crise da hegemonia militar, com objetivos contra hegemônicos. Uma das questões centrais do texto, que vamos abordar mais adiante é: estaria sendo produzido, mais recentemente, um novo consenso no campo da saúde por empresários e entidades empresariais?

Por fim, a ideia de terceira via, formulada pelo sociólogo inglês Anthony Giddens, como explicação para o papel do Estado pós-Guerra Fria é também crucial para as compreensões do livro sobre a constituição do SUS. Por essa visão, o "Estado de bem-estar" do pós-Segunda Guerra é, no final do século, substituído pela "sociedade de bem-estar”, que privilegia as parcerias entre sociedade e Estado ou entre público e privado. Assim o Estado não seria nem mais intervencionista nem mínimo, mas um Estado "gerencial" ou "necessário", no sentido de que seria o responsável por regular essas parcerias num movimento de "descentralização participativa". O Estado passa a fazer concessões, e o empresariado entra em novos espaços antes restritos ao "público" (educação e saúde, por exemplo), se tornando responsável pelo desenvolvimento nacional (ainda que boa parte dessas empresas sejam multinacionais) - no Brasil, as OS ou Organizações Sociais são estratégia e exemplo central para essa descentralização do Estado, consistindo em organizações privadas não-estatais, que recebem dinheiro e recursos públicos para administrar bens pertencentes ao Estado. Essa nova ordem mundial "pós-tradicional" é resumida pela autora em três pilares: novo Estado democrático "gerencial"; sociedade civil ativa; e individualismo como valor moral radical. No Brasil, esse processo se inicia em meados da década de 80 , quando a ideia 
de "sociedade civil" surge com força, fazendo com que crescesse a articulação e participação política de variados grupos sociais, numa ideia de "cidadania ativa" - envolvendo empresas, ONGs e cidadãos articulados na execução de políticas sociais. Ideia de um pacto social, unindo a sociedade civil numa cultura de colaboração em prol do desenvolvimento nacional, apaziguando a luta de classes.

O primeiro capítulo do livro (“A Política Nacional de Saúde (PNS) em Perspectiva Histórica: 1960 a 1990"), de tom mais parecido com o livro de Menicucci, analisa o surgimento das entidades empresariais - eixo central de análise - nas décadas de 1960 e 1970 e sua rearticulação em 1980, em contexto de uma nova conjuntura; em paralelo com os rumos das políticas de saúde no período. Como apresentado na resenha anterior, nas décadas de 1960 e 1970, com as IAPs e depois com o INPS, a principal política de saúde estatal foi a da compra de serviços privados, de forma direta ou via subsídios a empresas. Além disso, o governo militar insere um número enorme de pessoas, antes descobertas de qualquer assistência à saúde, na previdência, trazendo uma nova demanda enorme para o setor. Esse período, de grande crescimento, fez com que os empresários começassem a se organizar em entidades para a defesa de seus interesses, a princípio, uns em disputa contra os outros pelos recursos previdenciários estatais. Algumas das principais entidades que surgem, a princípio, são: CMB, dos hospitais filantrópicos (1963); $\mathrm{FBH}$, dos hospitais particulares (1966); Abramge, das empresas de medicina de grupo (1966); e a Unimed, das cooperativas médicas (1972).

Desde 1968, com o INPS, Estado centraliza completamente a compra dos serviços de saúde (modelo Estatal-burocrático-privatista), através do Ministério da Previdência e Assistência Social (MPAS), que se torna o responsável exclusivo pela saúde individual (curativa, ligada ao bem-estar do indivíduo, âmbitos hospitalar e farmacêutico), o Ministério da Saúde (MS), em oposição, perde forças e se torna responsável somente pela saúde coletiva 
(interdisciplinar, ligada a políticas sociais de prevenção em saúde: vacinas, controle de epidemias, saúde da família, campanhas de conscientização e assim por diante); a partir de 1974, com o colapso do milagre econômico, empresários nacionais e internacionais (estes principalmente ligados à indústria farmacêutica e de equipamento hospitalares) começam a se organizar para influenciar políticas estatais, e tentar quebrar esse monopólio estatal. Esse sistema começa a colapsar por conta dos altíssimos pagamento cujo INPS necessitava arcar, assim surge necessidade de reformular a política: convênios-empresa são extintos e pagamento aos serviços privados passa a ser por conjunto de atos com valores pré-estabelecidos (o que é muito mais barato do que o modelo anterior, que pagava por ato realizado).

Nesse momento, há por um lado uma crescente articulação dos empresários, com criação da Fenaess (Federação Nacional dos Estabelecimento de Serviços de Saúde, em 1983), mas também a crescente força e infiltração por parte do movimento sanitarista no MS e no MPAS, defendendo uma pauta publicista. Ambos grupos serão muito importantes nos debates constituintes, alguns anos depois, representando posições opostas. FBH, Abramge e Fenaess, aliados aos laboratórios farmacêuticos (ALANAC), se articularam em um posicionamento anti estatização, em defesa da não-regulamentação estatal e de um livre mercado da saúde. Essa posição foi simbolicamente representada pela posição do grupo contrária à presença do "direito à saúde" na constituição, defendendo em seu lugar o "direito de proteção à saúde", restringindo a saúde ao âmbito médico-hospitalar - posição que foi derrotada. Assim, a luta do setor privado na Assembleia Constituinte - com exceção dos hospitais filantrópicos, que defenderam o SUS - foi por "minimizar os danos" e tentar garantir a livre-iniciativa privada suplementar. Obtiveram êxito, garantindo a ampliação das possibilidades de atuação das empresas de saúde. 
O segundo capítulo (“Entidades empresariais e a Política Nacional de Saúde (PNS): do confronto à colaboração público-privada") está centrado em analisar a Confederação Nacional de Saúde (CNSa) como representante dos setores dominantes, e a sua capacidade de organização e inscrição de seus interesses no âmbito da sociedade civil e do Estado, consolidando a colaboração público-privada na PNS. A CNSa surge em 1994, como tentativa de articular sob seu "guarda-chuva" todas as entidades empresariais de saúde, se constituindo sindicato patronal máximo da saúde. Como o livro demonstrará, deu força política e institucional ao setor privado, além de organizar pautas comuns. Por fim, a categoria "confederação" dava à entidade poderes de propor ADIs (Ações Diretas de Inconstitucionalidade) no STF; de possuir assentos em tribunais do trabalho e de administração de contribuições sindicais compulsórias e recursos do Sistema S.

O capítulo começa demonstrando como o SUS se enfraqueceu por ser implementado simultaneamente, e na contramão, de reformas estatais de tendência neoliberal - com apoio de organizações internacionais como o Banco Mundial - que estimulavam a criação de PPPs, e dos objetivos dos governo Collor e depois FHC, que reduziram significativamente o repasse de verbas ao SUS. Hospitais filantrópicos, antes aliados do SUS, nos anos 2000 se aproximam dos planos e seguros de saúde, passando a atender no mesmo hospital ao setor público e suplementar, com valores distintos para "garantir sobrevivência". Serviços privados se fortaleceram muito com subsídio estatal indireto (incentivos e isenções fiscais) - em 2011, por exemplo, $25 \%$ dos brasileiros estavam vinculados a um plano privado de saúde. Aos poucos, começa a crescer o número de propostas reformadoras, pressionando hospitais públicos a atender aos "novos parâmetros de gestão" (flexibilização da gestão, terceirização de partes, tecnologias de informação e comunicação[...]). OSSs servem a essas mudanças almejadas, garantindo contratações sem concurso, recursos extraorçamentários e compras sem licitação. 
No âmbito das entidades empresariais também acontecem grandes mudanças a partir do surgimento da Fenaess e sobretudo da CNSa, que nasce se desvinculando da Confederação Nacional do Comércio em disputado processo, liderado pela FBH e CMB. A partir desse momento, a cultura de confronto entre os setores empresariais é substituída por uma de colaboração. Surgem também novas associações no período, vinculadas (Anahp, dos hospitais privados; Unidas, das instituições de autogestão em saúde; e Fenasaude, da saúde suplementar. Surge também ONA - Organização Nacional de Acreditação, aliada à CNSa, responsável por por implementar novas técnicas de avaliação e certificação de qualidade dos serviços de saúde).

A seguir, o livro apresenta as ADIs propostas pela CNSa no STF, sempre defendendo os direitos das empresas perante aos dos trabalhadores e contra interferência estatal. Outra grande agenda da CNSa, detalhada no capítulo, é a criação de um "Sistema S da saúde", com a criação do Sess e Senass (equivalentes ao Sesc e Senac), aumentando assim seus recursos e dispondo da capacidade de criar ações e capacitações voltadas para a área de saúde, sob a justificativa de que "saúde não é comércio" e sim serviço. Em contraponto, o livro mostra como a saúde tem se tornado cada vez mais um business, e que possui um tripé de sustentabilidade (de acordo com empresários da área): meio ambiente, gestão de pessoas e resultado financeiro. Propostas calcadas no avanço tecnológico, ligado ao setor financeiro internacional, e na precarização das relações de trabalho. Assim empresas de saúde começam buscam conquistar lealdade dos clientes através dos serviços e de responsabilidade social, por exemplo, se parecendo cada vez mais com qualquer outra empresa ou negócio.

Finalizando o capítulo, ainda cita uma série de eventos organizados por e para empresários, desde 1964, como forma de mapear as relações e influências das atividades empresariais - de um setor do mercado em relação ao outro e do setor empresarial de forma geral em relação à política - pela análise dos temas debatidos e participantes envolvidos nos 
eventos. Os eventos, especialmente a partir da década de 90 vão confirmando as teses do livro: cada vez mais têm a presença de figuras importantes do setor público, marcando colaboração público-privada; cada vez mais presenças de pessoas e empresas estrangeiras, confirmando a internacionalização do setor; confirmam a nova agenda conjunta e colaborativa das entidades do setor privado; mostram o fomento e defesa de novas formas de gestão de "terceira via", com tendências neoliberais; o incentivo à novas formas de gestão, pagamento e PPPs pela OMS e Banco Mundial; o incentivo à ideia de sustentabilidade e ecologia (interesses de longo prazo do capital); e assim por diante.

O terceiro e último capítulo (“Interfaces entre valores, ideias e práticas públicas e empresariais de saúde"), busca analisar o impacto das entidades empresariais nos fóruns de deliberação da PNS e suas influências no desenvolvimento das políticas de saúde nos anos 90-2000. Este capítulo busca tentar responder a hipótese, apresentada anteriormente, se as empresas conseguiram ou não criar um novo consenso dentro da política brasileira de saúde. Para responder à questão, a autora traz um levantamento de informações sobre as interfaces entre a CNSa e entidades filiadas e três instâncias importantes na formulação da PNS: o Conselho Nacional de Saúde (CNS), a ANS e o Banco Nacional de Desenvolvimento Econômico e Social (BNDES).

O CNS é a instância de discussão e deliberação da PNS, bem como de controle de sua execução. Vinculada ao MS, materializa o princípio de participação e controle social do SUS, via conselhos de saúde, ali representados. As entidades empresariais (CNSa, Fenaess, FBH e CMB) possuem representantes, assim como os trabalhadores e usuários do SUS, o poder público e entidades científicas. A composição dos membros conselho tende mantê-lo favorável a um SUS forte, universal e igualitário, que controle ações e serviços, sejam públicos ou privados, e que regule e subordine a saúde suplementar a seus princípios. O capítulo apresenta as principais pautas de debate no Conselho, e a sua luta para garantir 
financiamento público adequado ao SUS, apoiada inclusive pelos empresários da saúde. Por outro lado, a escassez de recursos motivou uma série de parcerias entre o SUS e o setor privado, em troca de uma série de contrapartidas ao setor (isenções, auxílios, créditos) acordos apoiados inclusive pelo grupo dos "defensores do SUS". A regulação do setor privado era pauta constante dentro do Conselho; as entidades empresariais, evidentemente contra essas e outras pautas (por exemplo as trabalhistas, de redução da carga horária), a princípio só participavam de comissões técnicas. Ao longo dos anos, conseguiram participar também de comissões intersetoriais e grupos executivos, aumentando sua influência.

A ANS, por sua vez, é uma entidade ao redor da qual os empresários criam forte articulação. Até por isso, paulatinamente, vai se distanciando da CNS. Passa a servir principalmente como espaço para debate e defesa de demandas do setor privado: a regulamentação de vínculos entre mercado e prestadores de serviços; cadastramento de empresas de planos e seguros; menor ressarcimento ao SUS; isenção ou abatimento fiscal para usuários dos planos de saúde e estabelecimentos; profissionalização e modernização da gestão dos negócios em saúde; estímulo a PPPs; dentre outras. Funciona também estimulando e facilitando a troca de informações entre prestadores e operadores do setor privado; cria também índice de qualificação, para ranquear quais os melhores hospitais; e apoia a criação da ONA, no mesmo caminho de estimular padrões mais "modernos" de qualidade assistencial - importante pontuar que essas demandas são voltadas inclusive, ou até principalmente, para aquelas OSSs que atendem pelo SUS, privadas ainda que não-lucrativas. Isso tudo mostra como a ANS se tornou um espaço de defesa de propostas de terceira via, apresentadas anteriormente, mostrando a permeabilidade da agência aos interesses dos setores empresariais, que inclusive compõe a maioria de sua diretoria.

Por fim, o BNDES é apresentado como outro exemplo de como as entidades empresariais construíram uma nova hegemonia dentro da aparelhagem estatal. Nos últimos 
anos, hospitais particulares vêm recebendo uma série de financiamentos públicos por parte do BNDES, e com incentivo da ANS, para sua readequação a parâmetros de qualidade de assistência difundidos por eles próprios - a justificativa principal é que instituições privadas conveniadas representam boa parte da oferta de serviços públicos de saúde, ainda que sejam também conveniadas com planos de saúde. Além disso, surgem linhas de crédito específicas para hospitais filantrópicos. Os considerados de excelência (Albert Einstein, Sírio Libanês, Oswaldo Cruz e Samaritano (São Paulo); Moinhos de Vento (Porto Alegre) e Mater Dei (Belo Horizonte)), receberam investimentos de 1,2 bilhão de crédito a juros baixíssimos em troca de serviços prestados ao SUS: formação de recursos humanos, apadrinhamento de hospitais públicos, transferência de tecnologias de gestão, cursos, pesquisa e outros mais. Como se vê, as empresas e entidades representativas se utilizam muito do discurso da crise no SUS para fortalecer seus interesses e sua penetração dentro do aparelho estatal.

Concluindo, brevemente, o livro de Braga procurou demonstrar a ampliação da organização política coletiva dos empresários, principalmente após a criação da CNSa, e como estes conseguiram assim influenciar as instâncias estatais de formulação da política nacional de saúde, modificando severamente a atuação dos serviços públicos de saúde e garantindo seus interesses, ideias e práticas, cada vez mais fortalecidos e atendidos - em detrimento de um projeto publicista para a saúde no Brasil.

\section{Análise - diferenças metodológicas, conflitos e complementaridades entre as teses}

As concepções teóricas de ambos os livros não exatamente se negam. Em certa medida, na verdade, as metodologias são compartilhadas, o que as diferencia é a tônica: para Menicucci, o foco central são as instituições, como as decisões políticas prévias impactaram de forma irreversível a assistência à saúde brasileira; enquanto Braga, partindo de uma 
concepção bastante mais materialista, tem como eixo central o conflito de classes e a permeabilidade do Estado para com os interesses empresariais. Menicucci não nega a importância dos interesses de classe na história institucional da saúde brasileira, nem Braga a importância dos efeitos de path dependence e feedback para a constituição do SUS (inclusive dedica um capítulo a isso) - novamente, a diferença entre as teses é a preocupação central de cada.

Ainda assim, é possível dizer que as análises são de escalas distintas. O primeiro livro é de fôlego bastante maior, perpassando boa parte da história da república brasileira e observando igualmente as ações do setor público e privado e as interações entre ambos. O segundo é mais restrito, ainda que apresente uma análise bastante detalhada. Assim, esta análise compreende um período menor (a primeira década e meia do século XXI), e está centrada principalmente na análise do setor privado, mais especificamente das entidades empresariais e mais especificamente ainda da CNSa - que tem sua origem, composição, propósitos e atuação densamente apresentados e analisados.

A complementaridade histórica, já mencionada, também é importante, o livro de Menicucci termina sua análise no final do século XX, com uma implementação do SUS ainda incipiente e até mesmo uma "previsão" de que haveria um aumento da participação estatal na Saúde (o que o outro livro, e o tempo, refutam); a tese da Braga, por sua vez, demonstra como a entrada dos interesses empresariais no Estado acabaram transformando o SUS, na prática, em algo completamente diferente dos projetos do movimento sanitarista ou do que estava previsto na Constituição (projetos estes tão bem explicados por Menicucci), ou seja, está inserida principalmente num período histórico de implementação do SUS, mais recente, já dos anos 2000 em diante.

Exemplo de como a leitura dos textos pode ser complementar: Menicucci apresenta detalhadamente toda a articulação do movimento sanitarista desde os princípios até os debates 
da Constituinte e a consolidação de um projeto que é bastante inovador e disruptivo (ainda que pontue que existem também diversas continuidades), de uma saúde pública, gratuita, desvinculada de contratos de trabalho, municipalizada e universal. Braga, por sua vez, nos mostra como ao longo dos anos, empresários se articularam fortemente, se inseriram em posições estratégicas e conseguiram impor várias de suas pautas, alterando bastante o funcionamento do SUS na prática. Assim, apesar de teoricamente universal, na prática ele se torna voltado a um determinado segmento da população (ainda bastante grande), enquanto outra parte continua utilizando os serviços do mercado da saúde. Além disso, com uma série de parcerias público-privadas, o próprio SUS se torna dependente do setor privado principalmente via OSSs, assim vários estabelecimentos que atendem via SUS são geridos pelo setor privado; além das parcerias com grandes hospitais apresentadas acima, dentre outros exemplos possíveis. Assim, o sistema dual de saúde, apresentado por Menicucci, se torna bastante mais confuso com as informações apresentadas na pesquisa de Braga, uma vez que ambos os sistemas acabam se influenciando, misturando e dependendo um do outro. De forma com que o projeto público saia enfraquecido.

Outro caso de complementaridade é em relação às próprias entidades empresariais foco central do livro de Braga. Menicucci dedica alguma atenção a esses grupos, e mostra como eles surgem em um período de alta competitividade e concorrência entre os diversos setores do mercado, e como as entidades surgem para tentar fortalecer os subgrupos (empresas de medicina em grupo, cooperativa, hospitais...) uns perante os outros. Braga, por sua vez, mostra como a partir da articulação criada no final da década de 80 , as entidades, apesar de ainda preservarem algumas divergências entre si, passam a lutar cada vez mais por pautas conjuntas e unificadas, substituindo a cultura de concorrência por uma de colaboração.

Ao fim e ao cabo, é possível também dizer que Braga leva a tese de Menicucci ainda mais a fundo. Se Menicucci quer demonstrar como os efeitos de path dependence e feedback 
das políticas prévias de saúde enfraqueceram e limitaram a inovação gerada pelo SUS, já no texto constituinte e em sua incipiente implantação. Braga mostra como ao longo dos anos posteriores à essa análise, esse processo aconteceu de forma ainda mais radical, com as entidades se inserindo profundamente em diversos espaços de tomada de decisão das políticas estatais e alterando drasticamente o que uma vez se concebeu que seria o Sistema Universal de Saúde.

\section{CONCLUSÃO}

Os livros "Público e privado na política de assistência à saúde no Brasil: atores, processos e trajetórias”, de Telma Menicucci e "Empresariado e políticas públicas de saúde no Brasil contemporâneo", de Ialê Falleiros Braga são duas importantíssimas e originais análises sobre o sistema de saúde brasileiro, políticas nacionais de saúde e suas formações.

Os estudos possuem várias diferenças entre si: época de publicação, período analisado, foco da análise, metodologia, referencial teórico e assim por diante. Ao mesmo tempo, são dois livros bastante complementares em suas análises e que, se lidos conjuntamente, podem formar um panorama bastante completo e amplo da formação da saúde brasileira até os dias de hoje.

\section{REFERÊNCIAS}

BRAGA, I. F.. Empresariado e Políticas Públicas de Saúde no Brasil Contemporâneo. Rio de Janeiro: Ed. Fiocruz, 2018

FALLETI, T. G. Infiltrating the State: the evolution of health care reforms in Brazil, 1964-1988. In: MAHONEY, James; THELEN, Kathleen. Explaining institutional change: ambiguity, agency and power. Cambridge: Cambridge University Press, 2010. p. 38-62.

FERNANDES, A. S. A. Path dependency e os estudos históricos comparados. BIB - Revista Brasileira de Informação Bibliográfica em Ciências Sociais, n. 53, p.79-103, 2002. 
GRAMSCI, A. Cadernos do Cárcere: introdução ao estudo da filosofia e a filosofia de Benedetto Croce. v. 1. Rio de Janeiro: Civilização Brasileira, 2001a.

GRAMSCI, A. Cadernos do Cárcere: os intelectuais, o princípio educativo, jornalismo. v. 2. Rio de Janeiro: Civilização Brasileira, 2001b.

GRAMSCI, A. Cadernos do Cárcere: Notas sobre o Estado e apolítica. v. 3. Rio de Janeiro: Civilização Brasileira, 2002.

MENICUCCI, T. M. Gonçalves. Público e Privado na Política de Assistência à Saúde no Brasil. Rio de Janeiro: Ed. Fiocruz, 2007

POUlAntZAS, N. O Estado, o Poder, o Socialismo. Rio de Janeiro: Graal, 2000. 